\title{
Computer-Aided Cognitive Rehabilitation of Stroke Patients in Cognitive Function and Research on the Ability to Their Daily Living
}

\author{
Seung-Kyu Park', Dae-Jung Yang ${ }^{1}$, Jeong-II Kang'1, Je-Ho Kim¹, Dong-jin Jeong ${ }^{2}$ \\ 'Department of Physical Therapy, Sehan University; ${ }^{2}$ Department of Physical Therapy, Graduate School, Sehan University, Yeongam-gun, \\ Jeollanam-do, Korea
}

Purpose: The purpose of this study was to evaluate the impact of differences in computer-aided cognitive rehabilitation aimed at stroke patients on cognitive function and daily life.

Methods: The study subjects were Gwangju, Jeonnam including the attention group (group I), memory group (group II), and visual perception group (group III), who were randomly placed in each of a 10 by one problem solving group (group IV). The PSSCogRehab was applied to all subjects who underwent eight weeks once a week after 20 minutes in each group by strengthening mediation 10 minutes 30 minutes total, with a five minute break in the middle.

Results: Cognitive function and activities of daily living is security and inter-group differences before intervention, and post-test results in the memory training group II, the intervention group I, III, IV and more on cognitive function and activities of daily living compared to it was effective.

Conclusion: The results of computer-aided cognitive rehabilitation measuring cognitive function and ADL in patients with stroke in accordance with the group I, III, and IV group cognitive function and activities of daily living compared to IV showed that it was more effective.

Keywords: Stroke, Cognition, Activities of daily living, Computer-aided cognitive rehabilitation.

\section{서 론}

대한민국 전체 인구 대비 높은 사망률을 차지하고 있는 뇌졸중은 최 근 노령 사회가 되어갈수록 발병빈도와 사망률이 날로 증가하고 있 으며, 50대에서 60대뿐만 아니라 최근에는 젊은 층에서도 주 사망원 인으로 보고되고 있다. 뇌졸중 이후 $25 \%$ 에 해당하는 환자가 치매 증 상을 보이며, $50-75 \%$ 의 환자가 인지기능장애를 보이는 것으로 나타 났다. 인지기능(Cognition)이란 흔하게 일상생활에서 일어나는 일반 적이고 특정적 문제를 해결할 수 있는 기억력(Memory), 집중력(Attention), 시지각력(Visual Perception), 문제해결력(Problem Solving), 판 단력(Judgement), 추상적인 사고(Abstract thinking), 통찰력(insight), 계 획력(Plan), 억제력(inhibition) 등이 있으며 뇌졸중 후 인지기능장애 는 운동기능의 장애, 정신장애 및 일상생활수행능력의 제한과 함께

Received Oct 15, 2015 Revised Oct 20, 2015

Accepted Oct 25, 2015

Corresponding author Dong-jin jeong

E-mail zzass0809@nate.com
재활에 있어서 가장 문제 되는 장애 중 하나이기 때문에 뇌졸중 및 뇌손상 환자들의 재활 프로그램을 위하여 인지기능의 정확한 평가 와 중재가 요구된다. ${ }^{4}$

일상생활동작이란 기본적 일상생활동작과 도구적인 일상생활활 동으로 나뉘어지며, 식사하기, 옷입기, 목욕하기, 대소변조절, 개인위 생, 화장실이용, 보행 및 휠체어 사용하기 등 이동능력과 지역사회에 서의 이동, 쇼핑하기, 식사준비 등으로 분류할 수 있다. ${ }^{5}$ 뇌졸중 환자 는 인지기능장애로 일상생활의 불만족과 사회활동의 참여를 제한 받으며, 그로 인해 자신의 지위와 역할을 상실하게 되면서 자존감이 저하되어 전반적으로 일상생활수행능력과 삶의 질에 부정적으로 작 용하게 된다. ${ }^{6} \mathrm{Chen}$ 등 은 일상생활동작과 인지기능의 상관관계를 연 구한 결과 인지기능장애를 해결할수록 일상생활수행능력이 유의하 게 증가하였다고 보고하였다.
Copylight (C2015 The Korea Society of Physical Therapy

This is an Open Access article distribute under the terms of the Creative Commons Attribution Non-commercial License (Http:// creativecommons.org/license/by-nc/3.o.) which permits unrestricted non-commercial use, distribution, and reproduction in any medium, provided the original work is properly cited. 
국내에서 주로 이루어지고 있는 인지재활치료는 약물치료를 동반 한 전통적인 인지재활치료와 컴퓨터를 이용한 전산화 인지재활치료 등이 있다. 전통적인 인지재활치료는 주로 치료사가 환자의 인지기능 장애 수준에 따라 펜과 종이를 사용하여 주어진 책상 위에서 직접 쓰거나 그리는 방법이며, ${ }^{8}$ 또한 기억력향상을 위한 퍼즐이나 카드를 이용하여 게임형식으로 진행하는 치료방법과 환자의 인지기능을 향 상시키기 위한 목적으로 기능적 활동 훈련을 하는 방법 등이 있다. ${ }^{9}$ 하지만 전통적 인지재활은 제한된 환경에서 치료사에 의해 의존적 인 훈련을 하며 일정한 피드백이 없다는 단점이 있다. ${ }^{10}$

1980년대부터 컴퓨터가 일반화되기 시작하면서 인지훈련에 사용 하려는 시도가 보이기 시작하였다. 컴퓨터를 이용한 전산화 인지재 활치료는 Glisky 등 ${ }^{10}$ 의 연구에서 기억력 훈련을 시작한 계기로 많은 치료사들이 사용하게 되었다. 전산화 인지재활치료는 시각적 정보처 리 모델 이론을 기반으로 하였고, 뇌졸중 및 뇌손상 노인의 주의집중 력과기억력 향상에 효과적이라고 보고되었다.

전산화 인지재활치료는 컴퓨터를 이용하기 때문에 치료사의 개입 시간이 줄어들고, 수행결과에 대하여 환자가 바로 확인할 수 있어 치 료에 대한 동기부여를 할 수 있다. 또한 치료사가 객관적이고 정확한 정보를 환자에게 피드백할 수 있다는 장점이 있다. ${ }^{9}$

전산화 인지재활치료효과에 관한 기존의 연구들을 살펴보면 Flak 등ㅁ은 뇌 손상 환자 및 기억력 손상환자를 대상으로 전산화 인지재 활치료의 효과를 확인하였다. 또한 Garrido 등 12 은 정신분열 및 집중 력저하환자를 대상으로 삶의 질, 인지기능 및 자존감을 상승시키는 효과가 있음을 확인하였다. 또한 Cipriani 등 13 은 알츠하이머와 경도인 지장애환자를 대상으로 전산화 인지재활치료가 기억력, 시지각력, 식별하기 등의 학습 향상을 가져온다고 보고하였다. Cicerone 등 ${ }^{14}$ 은 뇌졸중 및 뇌손상 환자를 대상으로 인지재활치료를 실행하였을때 $92 \%$ 회복속도가 빨랐다고 보고하고 있다.

그러나 대부분의 선행연구가 전산화 인지재활치료와 전통적 인지 재활치료의 효과차이를 비교하거나 전산화 인지재활치료의 효과를 확인하는 데 그치고 있다. 즉 인지기능에 포함되어 있는 각 세부요소 들이 전체적인 인지기능 및 일상생활수행능력 등에 미치는 영향에
대한 연구들이 미흡한 실정이다. 따라서 본 연구는 재가 뇌졸중 환자 를 대상으로 인지기능의 세부요소들을 강화하는 방식으로 전산화 인지재활치료를 적용하고 이에 따라 전체적인 인지기능과 일상생활 수행능력에 미치는 효과의 차이를 확인하고자 한다. 이를 통해 뇌졸 중 및 뇌손상으로 인한 인지기능과 일상생활수행능력에 문제가 있 는 환자에게 알맞은 중재전략을 수립하고, 인지기능의 향상과 더불 어 삶의 질을 개선하는 데 필요한 세부요소를 파악하기 위한 기초자 료를 제공하고자 한다.

\section{연구방법}

\section{1. 연구대상}

본 연구는 2014년 10월부터 2015년 3월까지 진행되었다. 광주. 전남 지 역에 거주하시는 재가 뇌졸중환자 중 발병일로부터 최소 12 개월 이 상 36 개월 미만 경과된 자로 현재 약물복용을 하지 않는 대상으로 하 였으며, 연구를 시작하기 앞서 본 연구의 목적, 효과 및 성과에 대하 여 충분히 설명한 후 참여에 동의한 40 명을 대상으로 실시하였다. 대 상자는 인지기능에 영향을 미치는 물리치료나 작업치료를 받지 않 는 집에 상시 거주 중인 환자를 대상으로 하였으며, 세부적인 선정기 준은 한국형 간이 정신상태(MMSE-K) 19-24점의 경미한 인지장애 환 자, 일상생활동작척도 $(\mathrm{MBI})$ 를 사용하여 Moderate 이하의 환자, Motor Free Visual Perception을 통한 편측무시가 없고 시지각장애가 없는 환자, 시청각 분별력이 확실하고 건 측으로 치료에 임할 수 있는 환자 로 선정하였다(Table 1).

\section{2. 실험방법}

본 연구는 전산화 인지재활치료의 세부요소 중 집중력, 기억력, 시지 각력, 문제해결력에 대한 각각의 강화훈련 그룹으로 대상자를 배분 하였다. 집중력강화그룹(group I), 기억력강화훈련(group II), 시지각력 강화그룹(group III), 문제해결력강화그룹(group IV)으로 각 10 명씩 무 작위 배분하였다. 모든 그룹은 Flak 등1의 연구를 기반으로 8주, 주 3 회 20 분간 공통적으로 전산화 인지재활치료를 실시하였고, 5 분의 휴

Table 1. General characteristics of the subjects

\begin{tabular}{|c|c|c|c|c|c|c|}
\hline & Group I $(n=10)$ & Group II $(n=10)$ & Group III $(n=10)$ & Group IV $(n=10)$ & $\mathrm{F}$ & $p^{*}$ \\
\hline Height (cm) & $162.2 \pm 4.7$ & $166.7 \pm 5.6$ & $168.1 \pm 3.2$ & $162.9 \pm 6.2$ & 3.216 & 0.086 \\
\hline Age (year) & $72.0 \pm 5.9$ & $62.5 \pm 6.5$ & $69.8 \pm 5.4$ & $67.6 \pm 5.3$ & 4.857 & 0.080 \\
\hline Weight (kg) & $62.5 \pm 7.1$ & $67.2 \pm 11.9$ & $72.5 \pm 7.2$ & $67.0 \pm 6.3$ & 2.437 & 0.778 \\
\hline Stroke duration (month) & $20.2 \pm 4.1$ & $21.7 \pm 7.6$ & $21.0 \pm 6.7$ & $22.9 \pm 4.9$ & 0.366 & 0.034 \\
\hline MMSE-K (score) & $20.7 \pm 3.7$ & $20.9 \pm 4.1$ & $21.7 \pm 3.3$ & $20.9 \pm 3.1$ & 0.545 & 0.655 \\
\hline MBI (score) & $47.7 \pm 4.3$ & $44.8 \pm 7.8$ & $47.1 \pm 6.3$ & $46.8 \pm 3.7$ & 0.864 & 0.469 \\
\hline
\end{tabular}

Group I: Attention, Group II: Memory, Group III: Visual perception, Group IV: Problem solving

*p:one-way ANOVA. 
식 후 각 그룹별 추가적인 강화훈련을 20 분간 실시하였다. 중재 전후 환자의 인지기능수준과 일상생활수행능력을 측정하여 분석한다.

\section{1) 전산화인지재활프로그램(PSSCogReHab)}

본 연구에서는 재가 뇌졸중환자를 대상으로 인지훈련을 할 수 있도 록 고안한 PSSCogReHab (Bracy, Psychologicalsoftware Services, USA) 를 이용하였다. 인지기능장애에 따라서 뇌졸중, 치매, 중증 정신질환 등 신경정신질환 환자들에게 검증되었으며, 우울과 불안 등의 감정 장애 그리고 인지적 어려움을 지닌 아동 및 청소년들에게도 효과를 검증 받고 있다. 프로그램의 구성은 간단한 도움말과 훈련방법을 시 각적으로 제공하는 터치스크린, 자료 분석용 컴퓨터와 본 프로그램 이다. 45 개의 개별 프로그램들은 난이도에 따라 배분되어 있어 환자 의 인지기능장애 수준에 따라 단계적으로 적용할 수 있으며, PSSCo$\mathrm{gReHab}$ 은 집중력, 기억력, 시지각력, 문제해결능력을 훈련시키는 4 가 지의 항목으로 구성되어 있다. 특히 환자는 시각적으로 전달되는 훈 련의 크기, 훈련의 표시, 장소의 유무, 훈련의 간격, 동작속도, 처리방 법 등을 치료 실시 후즉시 피드백됨으로써 직접 수정 가능하다는장 점이 있다. ${ }^{15}$

\section{(1) 집중력강화프로그램}

실험자의 주거환경에 맞추어 주의력과 실행 능력을 훈련할 수 있는 기본 시각 반응훈련, 기본 선택적 시각 반응 훈련, 기본 청각 반응 훈 련, 기본 선택적 청각 반응 훈련, 시각 반응 분화 훈련, 시각 변별 분화 반응 훈련, 청각 신호 후 시각 반응 훈련, 시각 신호 후 청각 반응 훈 련, 시각 추적 훈련 1 , 시각 추적 훈련 2 , 목표물 추적 훈련 등의 집중 력 강화프로그램을 식탁 또는 침상 위에서 실시하였고, 실험과 무관 한 요인들의 환경을 줄이기 위해서 실험과 상관없는 물건과 환자의 산만을 가져 올수 있는 대상은 제거하였다.

\section{(2) 기억력강화프로그램}

실험자의 주거환경에 맞추어 시각적 분석, 언어적 분석, 개념 형성, 공 간감각적 적응, 회상 능력들을 통합한 공간 기억 훈련 (길 찾기), 순차 적 회상훈련 (기호화 위치 기억하기), 순차적 회상훈련 (단어, 숫자, 그 림), 역 순차적 회상 훈련 (숫자, 그림), 비순차적 회상 훈련 (숫자, 그림) 등의 기억력강화프로그램을 식탁 또는 침상 위에서 실시하였고, 실 험과 무관한 요인들의 환경을 줄이기 위해서 실험과 상관없는 물건 과 환자의 산만을 가져 올수 있는 대상은 제거하였다.

\section{(3) 시지각력강화프로그램}

환자의 주거환경에 맞추어 심층적인 공각 지각 분석 및 조합 능력을 요구하는 선 따라가기, 차별하기, 설계하기, 디자인 추측하기, 모양 및
패턴 훈련, 미로 찾기 등의 시지각력 강화프로그램을 식탁 또는 침상 위에서 실시하였고, 실험과 무관한 요인들의 환경을 줄이기 위해서 실험과 상관없는 물건과 환자의 산만을 가져 올 수 있는 대상은 제거 하였다.

\section{(4) 문제해결력강화프로그램}

환자의 주거환경에 맞추어서 고차원 인지 수준의 문제해결능력을 요 구하는 훈련인 추론하기, 피라미드, 십자놀이 훈련, 연역 추론 훈련, 숫자 퍼즐 훈련, 체커게임 훈련, 큐브게임, 순서배열 훈련 등의 문제해 결력 강화프로그램을 식탁 또는 침상 위에서 실시하였고, 실험과 무 관한 요인들의 환경을 줄이기 위해서 실험과 상관없는 물건과 환자 의 산만을 가져 올수 있는 대상은 제거하였다.

\section{3. 측정방법}

\section{1) 일상생활수행동작 평가 척도}

본 연구에서는 대상자의 일상생활수행능력을 확인하기 위해 Functional Independent Measure (FIM)를 사용하였다. FIM은 국내에서 가 장 활용도가 높은 일상생활수행능력 평가도구이며, 구성 타당도 및 내용 타당도가 여러 선행 연구에 의하여 이미 증명되었다. 일상생활 수행동작을 6 가지 영역으로 나누었으며 전체 18 개 항목으로 이루어 져 있다. 하위 항목에 대한 기능의 정도는 7점 척도로 나누어지고 최 소 점수가 18 점이며 최대 점수는 126 점이다.16

\section{2) 인지기능 평가 척도}

본 연구에서 사용한 인지기능 평가 도구는 Loewenstein Occupational Therapy Cognitive Assessment (LOTCA)로 이 도구는 지남력, 지각력, 시지각력, 사고조직력 4 가지 영역으로 구성되어 있고 각 항목은 총 26 개 하위항목으로 구성되어 있다. 각 항목은 최소 1점, 최대 4-5점으 로 채점되고 약 30-40분이 소요되며 집중도에 따라 2-3회로 나누어 검사 가능하다. 본 검사 도구는 성인 뇌졸중 및 뇌손상, 정상인을 대 상으로 표준화하였고, 검사자 간 신뢰도는 0.82-0.97로 신뢰할만한 도 구로 인정받고 있다.17

\section{4. 자료분석}

측정된 자료는 Window용 SPSS 18.0 을 이용하여 통계처리 하였으며, 네 집단 간의 동질성 검증을 위해 일원분산분석(one-way ANOVA)을 실시하였고, 중재방법에 따른 그룹 간 인지기능과 일상생활수행능력 의 유의성을 검증하기 위해 공분산분석(analysis of covariance, AN$\mathrm{COVA}$ )을 이용하여 분석하였고, 사후검정으로 scheffe를 사용하였 다. 통계학적 유의수준은 $\alpha=0.05$ 로 하였다. 
결 과

\section{1. 일반적인 특성}

연구대상자의 일반적 특성은 집중력 강화훈련그룹의 평균 나이 72.0 \pm 6.0 세, 신장 $162.2 \pm 4.7 \mathrm{~cm}$, 몸무게 $62.5 \pm 7.1 \mathrm{~kg}$, 유병기간 $20.2 \pm 4.1$ 개 월, MMSE-K 20.7 \pm 3.7 점, MBI $47.7 \pm 4.3$ 점이고, 기억력 강화훈련그룹 의 평균나이 $62.5 \pm 6.5$ 세, 신장 $166.7 \pm 5.6 \mathrm{~cm}$, 몸무게 $67.2 \pm 11.9 \mathrm{~kg}$, 유

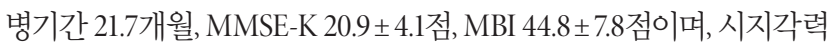
강화훈련그룹의 평균 나이 $69.8 \pm 5.4$ 세, 신장 $168.1 \pm 3.2 \mathrm{~cm}$, 몸무게 $72.5 \pm 7.2 \mathrm{~kg}$, 유병기간 $21.0 \pm 6.7$ 개월, MMSE-K $21.7 \pm 3.3$ 점, MBI $47.1 \pm$ 6.3점, 문제해결력 강화훈련그룹의 평균 나이 $67.6 \pm 5.3$ 세, 신장 162.9 $\pm 6.2 \mathrm{~cm}$, 몸무게 $67.0 \pm 6.3 \mathrm{~kg}$, 유병기간 $22.9 \pm 4.9$ 개월, MMSE-K $20.9 \pm$ 3.1점, MBI 46.8 3 3.7점으로 연구 대상자의 일반적 특성에 대한 각 집 단 간 유의한 차이를 나타낸 연구변수는 없었으므로 집단 간 정규성 분포를 보여 동일한 것으로 나타났다(Table 1).

\section{2. 그룹 간 인지기능 비교}

인지기능은 그룹 간 중재 전후 유의한 차이를 보였으며 $(\mathrm{p}<0.05)$ 사후 검정결과 기억력 훈련을 중재한 그룹 II가 그룹 I, III, IV와 비교하여 인지기능향상에 더 효과적이었다(Table 2).

\section{3. 그룹 간 일상생활수행동작 비교}

일생생활수행능력은 그룹 간 중재 전후 유의한 차이를 보였으며 $(\mathrm{p}<0.001)$ 사후검정결과 기억력 훈련을 중재한 그룹 II가 그룹 I, III, IV 와 비교하여 일상생활수행능력향상에 더 효과적이었다(Table 3).

\section{고 찰}

본 연구는 재가 뇌졸중 환자를 대상으로 인지기능의 세부요소들을 강화하는 전산화 인지재활치료가 전체적인 인지기능과 일상생활수 행능력에 미치는 영향을 확인하고자 하였다. 그 결과 집중력강화그 룹, 기억력강화그룹, 시지각력강화그룹, 문제해결력강화그룹 모두 대 상자들의 인지기능과 일상생활수행능력의 유의한 향상을 가져왔고, 특히 기억력강화그룹에서 가장 큰 향상을 보였다.

Fahimi 등 18 은 기억력강화프로그램(WMS)이 학생들의 기억력에 미 치는 효과를 알아보고자 72명을 대상으로 웩슬러 지능척도(K-wisc) 및 스피어 테스트(spear)를 이용하였고, 8 주간 총 10 회의 중재 이후 기 억력 강화 효과를 확인하였다. 그 결과 기억력 강화 훈련을 받은 학생 들의 평균 기억력 수치가 유의하게 증가함을 볼 수 있었다. 본 연구에 서 8 주간 주 3 회 강화그룹별 전산화 인지재활치료를 실시하였고, 그 결과 기억력강화그룹에서 가장 큰 인지기능의 향상을 볼 수 있었다. 선행 연구와 비교하여 대상자의특성, 훈련기간, 훈련 방법에는 차이 가 있지만 기억력강화그룹의 인지수준이 유의하게 향상된 결과는 기 억력향상훈련이 인지기능 향상을 위해 효과적이며 중요한 요소임을 뒷받침해 줄수 있을 것으로 생각된다.

Hellgren 등19은 단기기억력강화 프로그램을 성인 뇌졸중 및 뇌손 상 환자 48 명을 대상으로 20 주간 중재를 실시하여 기억력지수, 심리 상태, 일상생활수행능력 등을 평가하였다. 그 결과 기억력훈련이 환 자의 재활에 영향을 주었고, 단기기억력과 일상생활수행능력에 유의 한 영향을 미쳤다고 보고하였다. 특히 실험 이후 20 주 이상의 프로그 램을 사용하였을 때 효과가 더 큰 것으로 보고하였다. 하지만 본 연구 에서 중재기간은 Flak 등'의 연구를 토대로 8 주로 설정되어 20 주의

Table 2. Comparison of cognition between group

(Unit: score)

\begin{tabular}{|c|c|c|c|c|c|c|}
\hline & Group & Pre & Post & $\mathrm{F}$ & $p$ & Post-hoc \\
\hline \multirow[t]{4}{*}{ LOTCA } & Group I & $61.70 \pm 11.52$ & $65.00 \pm 12.03$ & 7.433 & $0.001^{*}$ & $\| I>I, I I I, I V$ \\
\hline & Group II & $53.90 \pm 16.59$ & $61.20 \pm 16.03$ & & & \\
\hline & Group III & $65.50 \pm 13.02$ & $67.40 \pm 12.53$ & & & \\
\hline & Group IV & $61.00 \pm 13.03$ & $64.30 \pm 12.52$ & & & \\
\hline
\end{tabular}

LOTCA: Loewenstein Occupational Therapy Cognitive Assessment, Group I: Attention, Group II: Memory, Group III: Visual perception, Group IV: Problem solving. ${ }^{*} \mathrm{p}<0.05$.

Table 3. Comparison of Activities of daily living between group

(Unit: score)

\begin{tabular}{lcccccc}
\hline & Group & Pre & Post & F & p & Post-hoc \\
\hline FIM & Group I & $49.00 \pm 9.38$ & $51.80 \pm 10.07$ & 7.605 & $\left\langle 0.000^{*}\right.$ & II>I, III, IV \\
& Group II & $46.80 \pm 2.82$ & $55.80 \pm 4.41$ & & \\
Group III & $50.20 \pm 7.89$ & $52.10 \pm 6.50$ & & \\
Group IV & $53.30 \pm 7.64$ & $59.20 \pm 5.20$ & & \\
\end{tabular}

FIM: Functional Independent Measure, Group I: Attention, Group II: Memory, Group III: Visual perception, Group IV: Problem solving. ${ }^{*} p<0.001$ 
중재기간을 가진 선행연구에 비해 짧지만 본 연구에서는 모든 그룹 을 대상으로 전체적인 인지재활치료를 실시한 이후 각 그룹별 강화 프로그램을 추가로 적용하였기 때문에 중재기간의 차이에도 불구하 고 유사한 결과가 나타난 것으로 사료된다.

$\mathrm{Kim}^{20}$ 은 근거중심 인지 훈련 프로그램이 뇌졸중 환자의 주의력과 기억력에 미치는 영향을 알아보고자 36 명을 대상으로 전산화 신경인 지기능 훈련 프로그램을 1 회 30 분, 1 주일에 3 회, 6 주간, 총 18 회 중재하 였다. 그 결과주의력과 기억력이 유의하게 상승되었다고 보고하였다.

Flak 등"의 연구에서는 50세 이상 뇌 손상 환자 및 기억력 손상환 자 30 명에게 5 주간 주 3 회 1 일 세션별 25 분 전산화 인지재활치료를 적 용하여 인지회복속도 및 일상생활수행능력에 미치는 영향을 확인하 고자 하였고, 그 결과 인지회복속도와 기억력의 유의한 증가가 있었 다고 보고하였다. 이와 같은 선행연구들의 결과는 전체적인 전산화 인지재활치료가 뇌졸중 혹은 뇌손상 환자들의 인지기능 세부요소 들과 일상생활수행능력의 향상을 가져올 수 있다는 것을 보여준다. 반대로 본 연구에서는 인지기능의 세부요소인 집중력, 기억력, 시지 각력, 문제해결력 등에 대한 강화훈련이 대상자들의 전체적인 인지 기능과 일상생활수행능력의 향상에 영향을 미친다는 것을 보여주고 있다. 이는 뇌졸중 환자의 인지재활치료와 일상생활수행능력 향상 을 위한 중재계획 수립에 있어서 각 대상자의 특성에 맞는 방식의 프 로그램을 선택하는데 있어 중요한 참고자료가 될 수 있을 것으로 사 료된다.

Maroti 등른 6 개월 이상 기억력결핍증상으로 인해 외래로 재활프 로그램을 받아온 만성 피로환자와 근육통 뇌수막염 환자 9 명을 실험 군으로 설정하였고 정확한 수치를 알아보고자 일반인 12 명을 대조군 으로 전산화 기억강화 프로그램 중재를 5 주간 주5회, 회당 30-45분 수행하였다. 그 결과 기억력결핍증상을 가진 실험군의 기억력 수치가 유의하게 영향을 미쳤고, 대조군은 뚜렷한 개선이 나타나지 않았다. 본 연구에서는 선행연구와 달리 대조군을 성정하지 않고 실험군 만 을 대상으로 연구가 이루어졌다는 점과 대상자의 수가 부족한 점을 이유로 본 연구에서 나타난 전산화 인지재활치료를 통한 효과를 뇌 졸중환자 혹은 다른 조건의 대상자로 일반화하는데 어려움이 있을 것으로 생각된다. 그러나 기존의 연구들과 달리 인지기능의 네 가지 세부요소들에 대한 전산화 인지재활치료 강화훈련 효과에 대해 살 펴봄으로써 뇌졸중환자의 인지치료에 대한 보다 구체적인 근거를 제 시할 수 있는 자료로 가치가 있을 것으로 생각된다. 또한 뇌졸중환자 의 일상생활수행능력 향상을 위해 대상자의 상태와 특성에 맞는 적 절한 인지기능 요소의 강화 훈련의 필요성을 제기할 수 있을 것으로 사료된다. 끝으로 전산화 인지재활치료를 통한 다양한 인지기능의 세부요소의 강화훈련 효과에 대한 추가적인 연구들이 지속적으로 이루어져야할 것으로 생각된다.

\section{ACKNOWLEDGEMENTS}

The Research has been conducted by the Research Grant of Sehan University in 2015 .

\section{REFERENCES}

1. Lee SR, Kwon HC. The Relationship Between Activities of Daily Living and Cognitive Score in Stroke Patients. J Kor Phys Ther. 2003;10(3):4151.

2. Desmond DW, Moroney JT, Paik MC et al. Frequency and clinical determinants of dementia after ischemic stroke. Neurology. 2000;54(5):112431.

3. Zinn S, Bosworth HB, Hoenig HM et al. Executive function deficits in acute stroke. Arch Phys Med Rehabil. 2007;88(2):173-80.

4. Loetscher T, Lincoln NB. Cognitive rehabilitation for attention deficits following stroke. Cochrane Database Syst Rev, 2000:4.

5. Jo DY, Park JH, Yoo UY. Effects of computer-based cognitive training on the cognitive function and instrumental activities of daily living in those with schizophrenia. J Korean Soc Occupational Therapy. 2006;21(1):114.

6. Madden S, Hopman WM, Bagg S et al. Functional status and health-related quality of life during inpatient stroke rehabilitation. Am J Phys Med Rehabil. 2006;85(10):831-8.

7. Chen X, Van Nguyen H, Shen Q et al. Characteristics associated with recurrent falls among the elderly within aged-care wards in a tertiary hospital: The effect of cognitive impairment. Archives of Gerontology and Geriatrics. 2011;53(2):183-6.

8. Bang YS. The effects of task-oriented activities on the cognitive function and performance of activities of daily living in stroke patients. J Korean Soc Occupational Therapy. 2007;15(3):49-61.

9. Kim DH, JO YN, Kwon HC. The effect of rehacom on cognitive function and activities of daily living for traumatic brain injury. Jounal of Special Education \& Rehabilitation Science. 2013;52(1):197-216.

10. Schuster B. Rehabilitation of TBI using RehaCom. European Journal of Physical and Rehabilitation Medicine. 2002;38(1):39.

11. Flak MM, Hernes SS, Skranes J et al. The Memory Aid study: Protocol for a randomized controlled clinical trial evaluating the effect of computer-based working memory training in elderly patients with mild cognitive impairment (MCI). Trials. 2014;15(1):156.

12. Garrido G, Barrios M, Penadés R et al. Computer-assisted cognitive remediation therapy: Cognition, self-esteem and quality of life in schizophrenia. Schizophr Res. 2013;150(2-3):563-9.

13. Cipriani G, Bianchetti A, Trabucchi M. Outcomes of a computer-based cognitive rehabilitation program on Alzheimer's disease patients compared with those on patients affected by mild cognitive impairment. Arch Gerontol Geriatr. 2006;43(3):327-35.

14. Cicerone KD, Dahlberg C, Malec J et al. Evidence-based cognitive rehabilitation: Updated review of the literature from 1998 through 2002. Archives of Physical Medicine and Rehabilitation, 2005;86(8):1681-92.

15. Bracy OL. PSSCogRehab [computer software].

16. Granger CV, Hamilton BB, Linacre JM. Performance profiles of the 
functional independence measure. Am J Phys Med Rehabil. 1993; 72(2):84-9.

17. Katz N, Itzkovich M, Averbuch S et al. Loewenstein Occupational Therapy Cognitive Assessment (LOTCA) battery for brain-injured patients: Reliability and validity. American Journal of Occupational Therapy. 1989;43(3):184-92.

18. Fahimi M, Arjmandnia AA, Fathabadi J. Investigating efficacy of "Working memory training software" on students working memory. Health. 2014;6:2236-44.

19. Hellgren L, Samuelsson K, Lundqvist A et al. Computerized training of working memory for patients with acquired brain Injury. Open Journal of Therapy and Rehabilitation. 2015;3(02):46.

20. Kim HH. The effects of evidence-based cognitive training program on the attention and memory of patients with stroke. Inje University. Dissertation of Master's Degree. 2008.

21. Maroti D, Westerberg AF, Saury JM et al. Computerized training improves verbal working memory in patients with myalgic encephalomyelitis/chronic fatigue syndrome: A pilot study. J Rehabil Med. 2015; 47(7):665-8. 